\title{
Comparison of Two Techniques for Surveying Headwater Stream Amphibians
}

Timothy Quinn, Marc P. Hayes, Daniel J. Dugger, Tiffany L. Hicks, and Annette Hoffman
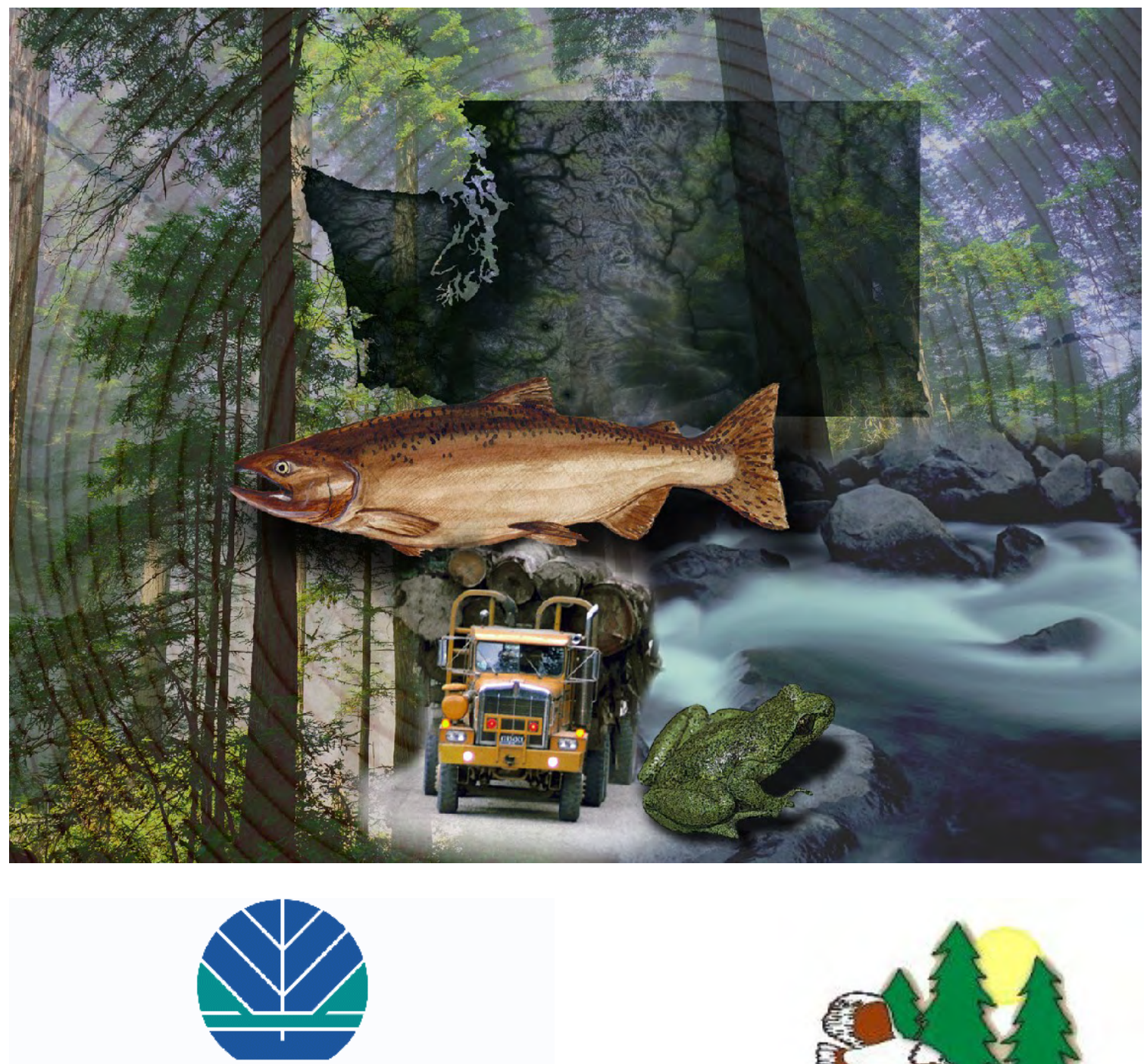

WASHINGTON STATE DEPARTMENT OF Natural Resources

Doug Sutherland - Commissioner of Public Lands

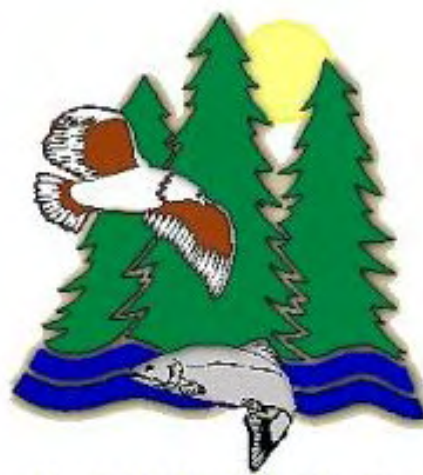

Cooperative Monitoring Evaluation \& Research

February 2007

CMER 01-101 


\section{Forest Practices Adaptive Management Program}

The Washington Forest Practices Board (FPB) adopted an adaptive management program in concurrence with the Forests and Fish Report (FFR) and subsequent legislation. The purpose of this program is to:

Provide science-based recommendations and technical information to assist the board in determining if and when it is necessary or advisable to adjust rules and guidance for aquatic resources to achieve resource goals and objectives. (Forest Practices Rules, WAC 222-12-045)

To provide the science needed to support adaptive management, the FPB made the Cooperative Monitoring, Evaluation and Research Committee (CMER) a participant in the program. The FPB empowered CMER to conduct research, effectiveness monitoring, and validation monitoring in accordance with guidelines recommended in the FFR.

\section{Disclaimer}

The opinions, findings, conclusions, or recommendations expressed in this report/product are those of the authors. They do not necessarily reflect the views of any participant in, or committee of, the Timber/Fish/Wildlife Agreement, or the Washington Forest Practices Board, or the Washington Department of Natural Resources, nor does mention of trade names or commercial products constitute endorsement of recommendation for use.

\section{Proprietary Statement}

This work was developed with public funding. As such, it is within the public use domain. However, the concept of this work originated with the Landscape and Wildlife Scientific Advisory Group (LWAG), the Amphibian Research Consortium (ARC), and the authors, and permission must be obtained from the originators to use the results in the way developed herein. Use of results without permission of LWAG, ARC, and the authors may be deemed a violation of federal statutes under the purview of the Office of Research Integrity. As a public resource document, this work should be given proper attribution and be properly cited. 


\section{Author Contact Information}

Timothy Quinn

Washington Department of Fish and Wildlife

600 Capitol Way North, Mailstop 43143

Olympia, Washington 98501-1091

quinntq@dfw.wa.gov

Marc P. Hayes

Washington Department of Fish and Wildlife

600 Capitol Way North, Mailstop 43143

Olympia, Washington 98501-1091

hayesmph@dfw.wa.gov

Daniel J. Dugger

(formerly) Washington Department of Fish and Wildlife

600 Capitol Way North, Mailstop 43143

Olympia, Washington 98501-1091

duggedjd@dfw.wa.gov

Tiffany L. Hicks

Washington Department of Fish and Wildlife

600 Capitol Way North, Mailstop 43143

Olympia, Washington 98501-1091

hickstlh@dfw.wa.gov

Annette Hoffman

Washington Department of Fish and Wildlife

600 Capitol Way North, Mailstop 43143

Olympia, Washington 98501-1091

hoffmah@dfw.wa.gov

\section{Full Reference}

Quinn, T., M. P. Hayes, D. J. Dugger, T. L. Hicks, and A. Hoffman. 2007. Comparison of two techniques for surveying headwater stream amphibians. The Journal of Wildlife Management 71(1):282-288. 


\section{Project Summary}

Several instream sampling methods have been developed for amphibians, but these methods have not been rigorously examined for their use in headwater streams. In particular, the cost of these methods, the rate at which they produce false negative errors (indicating a species is absent when it is actually present), and their ability to estimate abundance have not been compared. These factors were compared for two instream sampling methods, rubble-rousing and light-touch. Rubble-rousing is the most rigorous of instream sampling methods for amphibians, but it it is approximately 20 time more expensive to apply than light-touch. We found light-touch to be the method of choice for studies examining species presence, since it can produce low false negative error rates at at a relatively low cost compared to rubble-rousing. Assuming that rubble-rousing estimates of abundance are valid, light-touch can also estimate relative abundance for the Columbia torrent salamander (Rhyacotriton kezeri) with a reasonable degree of confidence, but this method cannot confidently estimate relative abundance for coastal tailed frog (Ascaphus truei). 


\title{
Comparison of Two Techniques for Surveying Headwater Stream Amphibians
}

\author{
TIMOTHY QUINN, ${ }^{1}$ Washington Department of Fish and Wildlife, Mailstop 43143, 600 Capitol Way N, Olympia, WA 98501, USA \\ MARC P. HAYES, Washington Department of Fish and Wildife, Mailstop 43143, 600 Capitol Way N, Olympia, WA 98501, USA \\ DANIEL J. DUGGER, Washington Department of Fish and Wildlife, Mailstop 43143, 600 Capitol Way N, Olympia, WA 98501, USA \\ TIFFANY L. HICKS, Washington Department of Fish and Wildlife, Mailstop 43143, 600 Capitol Way N, Olympia, WA 98501, USA \\ ANNETTE HOFFMANN, Washington Department of Fish and Wildlife, Mailstop 43143, 600 Capitol Way N, Olympia, WA 98501 , USA
}

\begin{abstract}
We compared rubble-rousing versus light-touch stream amphibian survey techniques in multiple 1-m plots across 10 streams in southwest Washington, USA. Specifically, we wanted to determine if light-touch surveys provide unbiased estimates of abundance (i.e., provide counts correlated with rubble-rousing counts) and which method would provide more cost-effective presence or absence information. Rubble-rousing, a common technique for surveying stream-associated amphibians in the Pacific Northwest, took 12 times as long as lighttouch to apply. Abundance estimates and standard errors for rubble-rousing were consistently higher than those for light-touch for all life stages for the coastal tailed frog (Ascaphus truei) and Columbia torrent salamander (Rhyacotriton kezeri). Except for eggs, light-touch detected all life stages found during rubble-rousing. For frogs, only some rubble-rousing abundance estimates, mostly involving second-year larvae, were highly correlated with their light-touch counterparts, whereas for salamanders, similar comparisons generated high correlations across most life stages. Correlations between methods were consistently greater for salamanders than for frogs. However the smaller tailed frog sample sizes and the cryptozoic nature of some life stages may have contributed to this pattern. Depending on the degree to which researchers can tolerate falsenegative error rates, light-touch may prove less costly than rubble-rousing for detecting species presence. For the cost of obtaining one rubblerousing sample, many light-touch samples can be used across a range of habitats for detecting species patchily distributed. (JOURNAL OF WILDLIFE MANAGEMENT 71(1):282-288; 2007)
\end{abstract}

DOI: $10.2193 .2006-342$

KEY WORDS abundance, Ascaphus truei, capture efficiency, false-negative error rate, headwater streams, occurrence, Rhyacotriton kezeri, stream-associated amphibians.

The most intensive survey method for stream-associated amphibians (SAAs) involves searching through unconsolidated stream substrate (hereafter, rubble-rousing) for animals. This technique has been used in conjunction with blocking stream sections with nets (e.g., Bury and Corn 1991, Wilkins and Peterson 2000) or not (e.g., Welsh and Lind 1996). Rubble-rousing is typically used to obtain occurrence and relative abundance data (e.g., Welsh and Lind 1996). This technique has also been used to estimate density (e.g., Bury et al. 1991) under the untested assumption that all individuals within a search area are detected. The high cost associated with rubble-rousing has impeded its application to large areas (Barr and Babbitt 2001), leading to the development of alternative methods (Diller and Wallace 1996, Pauley and Little 1998, Barr and Babbitt 2001, Adams and Bury 2002, Steele et al. 2003).

At the other end of the survey spectrum are relatively loweffort (per unit area) visual surveys that rely on opportunistic sighting of amphibians (Crump and Scott 1994; see also Thoms et al. 1997). Because these types of methods are less expensive per unit area, they typically are applied over larger areas (Crump and Scott 1994). Although visual survey methods are thought to provide reliable occurrence data (Barr and Babbitt 2001), amphibian studies have yet to address the question: do visual surveys provide valid estimates of abundance?

Light-touch survey methods represent a more recently developed class of low-effort (per unit area) survey

\footnotetext{
${ }^{1}$ E-mail: quinntq@dfw.wa.gov
}

techniques that involves visually searching an area and overturning movable surface objects (e.g., coarse woody debris and small boulders) to enhance detection of animals (Lowe and Bolger 2002). Researchers have applied lighttouch methods in pilot studies (Hayes et al. 2001) and other studies to survey longer stretches of stream at the expense of sampling smaller portions more thoroughly. These applications have been used to survey headwater amphibian populations that are patchily distributed (Welsh et al. 1997, Lowe and Bolger 2002, Steele et al. 2003, Russell et al. 2004; see also Downes 1990).

Survey methods designed to determine abundance either measure actual density or produce indices of abundance correlated with density (Lancia et al. 1996). Other desirable characteristics of abundance survey methods include low false-negative error rates (failure to detect a species when it is in fact present; Hayek 1994), low variance, and cost effectiveness. We compared 2 survey approaches (rubblerousing vs. light-touch) on the basis of these criteria using 2 SAAs (coastal tailed frog [Ascaphus truei] and Columbia torrent salamander [Rhyacotriton kezeri]) found in the headwater streams. We wanted to determine if light-touch surveys provided unbiased estimates of abundance (i.e., provided counts correlated with rubble-rousing counts) and which method would obtain the more cost-effective presence or absence information.

\section{STUDY AREA}

We conducted this study in the 11,856-ha Stillman Creek watershed in the Willapa Hills in the Coast Range 
physiographic province of southwest Washington, USA (Franklin and Dyrness 1973). Basin geology was 80\% igneous (mostly basalts) and 20\% marine sedimentary formations (Wells 1981). The basin was characterized by moderately steep topography (mostly $10-30 \%$ slopes) and managed forests composed of second-growth Douglas-fir (Pseudotsuga menziesii) trees. Mean annual precipitation varied from $90 \mathrm{~cm}$ at the lowest elevations $(250 \mathrm{~m})$ to $>250$ $\mathrm{cm}$ at the highest elevations (up to $948 \mathrm{~m}$; Sumioka et al. 1998).

We chose this region for its high amphibian species richness among forests in Washington (Dvornich et al. 1997), which are among the richest in the Pacific Northwest (Stebbins 2003).

\section{METHODS}

\section{Sampling}

Within the Stillman Creek basin, we selected 10 streams known to contain coastal tailed frogs (hereafter, tailed frogs) based on surveys conducted in previous years (M. Hayes, Washington Department of Fish and Wildlife, unpublished data). These streams were second- and third-order (Strahler 1952) and located upstream of fish as determined by electrofishing surveys (B. Fransen, Weyerhaeuser, unpublished data). We focused our analysis on 10 tailed frogoccupied streams because this species occurred less frequently than Columbia torrent salamander (hereafter, torrent salamander) in the study area and because finding zero animals using both survey methods is uninformative to our study. We systematically selected these 10 streams from a pool of 32 tailed frog-occupied streams to ensure representation across the apparent range of densities. We also avoided streams with forest stand ages $<15$ years old because harvest debris prevented effective instream sampling (Jackson et al. 2001). To select sampling units within the stream, we flagged each of the 10 streams into $10-\mathrm{m}$ segments. In each 10-m segment, we conducted a pilot survey to determine tailed frog occurrence. The intent of the pilot survey was to find occupied patches that would further increase the likelihood of finding tailed frogs for the techniques-comparison portion of the study. The pilot survey involved visually searching the wetted streambed, turning over easily moved surface objects, and visually noting the occurrence of tailed frogs, but it did not include otherwise disturbing animals or the streambed.

Within 7 days of a pilot survey, we compared survey techniques by conducting light-touch and rubble-rousing surveys on one randomly selected $1-\mathrm{m}$ belt from each tailed frog-occupied 10-m segment. This resulted in sampling 5$161-\mathrm{m}$ belts from each of 10 streams for a total of $761-\mathrm{m}$ belts. We randomly selected a $1-\mathrm{m}$ belt within the $10-\mathrm{m}$ segment to ensure that all types of habitat could be sampled. We set block nets on the up- and downstream ends of each 1 -m belt and conducted a light-touch survey immediately followed by a rubble-rousing survey. Light-touch surveys involved enumerating all animals by searching the wetted streambed and by turning over all easily moved surface objects (e.g., coarse woody debris, cobbles, and small boulders). Light-touch surveys are a subset of rubblerousing in the sense that a rubble-rousing begins by searching the streambed in a manner identical to lighttouch before proceeding to search within the deeper substrate. Prior to rubble-rousing, we did not replace animals we captured during the light-touch survey; we simply added them to the total number of animals resulting from rubble-rousing. We used standard rubble-rousing procedures (Bury and Corn 1991): we searched all substrate to a depth of $30 \mathrm{~cm}$ (or bedrock) in the wetted channel for amphibians, removed coarse substrate from the channel, and sifted the remaining fine substrate for animals. After each survey, we replaced the coarse substrate in the channel. Where shade limited visibility, surveyors used headlamps (Mega ${ }^{\mathrm{TM}}$ Petzl headlamps; Petzl America, Clearfield, UT) to illuminate the streambed.

We removed all amphibians we encountered and scored their life stages. For tailed frog this included eggs, first-year larvae, second-year larvae, metamorphs, and postmetamorphs. We distinguished larval year-classes based on size and hind limb development criteria (Bury and Adams 1999). Metamorphs had $\geq 3$ legs and a tail; postmetamorphs lacked a true tail. Aside from these stages, we also created a category termed second-year cohort; this combined secondyear larvae and metamorphs. We scored life-history stages for torrent salamanders as premetamorphs (individuals with gills) or postmetamorphs (individuals with no gills).

The Washington Department of Fish and Wildlife provides a programmatic permit to its research employees for capturing and handling animals. We handled animals using guidelines for use of live amphibians and reptiles in field and laboratory research (Beaupre et al. 2004).

\section{Statistical Analyses}

We assumed that rubble-rousing enumerated all individuals or enumerated a constant proportion of the total number of animals in an area and thus is either a true measure of density or a valid index of density (hereafter we use the term abundance to refer to either of these 2 cases). We further assumed that, as a measure of abundance, rubble-rousing is a standard against which light-touch could be evaluated. To our knowledge this assumption is untested. Nonetheless, our comparison is useful because rubble-rousing commonly is used and represents the most rigorous survey method available.

We calculated descriptive statistics on tailed frog and torrent salamander abundance (individuals $/ \mathrm{m}^{2}$, where area was stream width $\times 1$-m belt length) by life stage and by life-stage groups (e.g., all adults or all stages). We calculated mean abundance across all belts $(n=76)$ and across all streams (i.e., the mean of the belts within each stream; $n=$ 10).

Our count data were not normally distributed even after standard transformations (i.e., square root, logarithmic, and arcsine), so we considered nonparametric statistics most appropriate for comparing amphibian abundance. We used Wilcoxon signed-rank tests to compare abundance estimates 
Table 1. Mean abundance $\left(\right.$ no. $\left./ \mathrm{m}^{2}\right)$ and standard errors of coastal tailed frog and Columbia torrent salamander by life stage and life-stage group among 76 1-m belts across 10 streams and among 10 streams in the Stillman Creek basin, Washington, USA, 2003.

\begin{tabular}{|c|c|c|c|c|c|c|c|c|c|c|c|c|c|c|c|c|}
\hline \multirow[b]{3}{*}{ Life stage ${ }^{a}$} & \multicolumn{8}{|c|}{ Among 761 -m belts } & \multicolumn{8}{|c|}{ Among 10 streams } \\
\hline & \multicolumn{3}{|c|}{ Rubble-rousing } & \multicolumn{3}{|c|}{ Light-touch } & \multicolumn{2}{|c|}{ Wilcoxon } & \multicolumn{3}{|c|}{ Rubble-rousing } & \multicolumn{3}{|c|}{ Light-touch } & \multicolumn{2}{|c|}{ Wilcoxon } \\
\hline & $n^{\mathrm{b}}$ & no. $/ \mathrm{m}^{2}$ & SE & $n$ & no. $/ \mathrm{m}^{2}$ & SE & $Z$ & $P^{\mathrm{c}}$ & $n$ & no. $/ \mathrm{m}^{2}$ & SE & $n$ & no. $/ \mathrm{m}^{2}$ & SE & $Z$ & $P$ \\
\hline \multicolumn{17}{|l|}{ Tailed frog } \\
\hline Eggs & 2 & 0.49 & 0.48 & 0 & 0.00 & 0.00 & & & 1 & 0.63 & 0.63 & 0 & 0.00 & 0.00 & & \\
\hline First-yr larvae & 15 & 0.49 & 0.22 & 5 & 0.05 & 0.02 & -2.94 & 0.003 & 6 & 0.57 & 0.29 & 3 & 0.05 & 0.03 & -2.20 & 0.028 \\
\hline Second-yr larvae & 17 & 0.34 & 0.10 & 12 & 0.17 & 0.06 & -2.80 & 0.005 & 7 & 0.34 & 0.17 & 6 & 0.17 & 0.08 & -2.02 & 0.043 \\
\hline All larvae & 29 & 0.83 & 0.24 & 15 & 0.22 & 0.07 & -3.92 & $<0.001$ & 9 & 0.91 & 0.30 & 7 & 0.22 & 0.10 & -2.52 & 0.012 \\
\hline Metamorphs & 18 & 0.29 & 0.08 & 8 & 0.10 & 0.04 & -2.54 & 0.011 & 7 & 0.30 & 0.10 & 6 & 0.12 & 0.06 & -2.20 & 0.028 \\
\hline Second-yr cohort & 33 & 0.63 & 0.12 & 18 & 0.27 & 0.08 & -4.02 & $<0.001$ & 8 & 0.65 & 0.22 & 8 & 0.29 & 0.12 & -2.37 & 0.018 \\
\hline Postmetamorphs & 9 & 0.11 & 0.04 & 4 & 0.03 & 0.01 & -2.37 & 0.018 & 5 & 0.09 & 0.04 & 2 & 0.03 & 0.02 & -2.02 & 0.043 \\
\hline All stages & 43 & 1.72 & 0.57 & 22 & 0.35 & 0.09 & -4.86 & $<0.001$ & 9 & 1.94 & 0.83 & 8 & 0.37 & 0.13 & -2.52 & 0.012 \\
\hline \multicolumn{17}{|l|}{ Torrent salamander } \\
\hline Premetamorphs & 29 & 0.99 & 0.24 & 16 & 0.40 & 0.10 & 4.02 & $<0.001$ & 10 & 0.89 & 0.22 & 7 & 0.36 & 0.10 & 2.67 & 0.008 \\
\hline Postmetamorphs & 10 & 0.16 & 0.06 & 5 & 0.05 & 0.02 & 2.21 & 0.027 & 7 & 0.16 & 0.06 & 6 & 0.06 & 0.02 & 2.20 & 0.028 \\
\hline All stages & 31 & 1.15 & 0.27 & 20 & 0.45 & 0.11 & 4.20 & $<0.001$ & 10 & 1.06 & 0.25 & 9 & 0.41 & 0.10 & 2.67 & 0.008 \\
\hline
\end{tabular}

${ }^{a}$ Indented life-stage categories are composites of multiple life stages; second-year cohort is second-year larvae + metamorphs.

b Sample sizes $(n)$ are the number of 1 -m belts or streams with that life stage present; we calculated frequency of occurrence as $(n \times 100) / 76$ and $(n \times 100) /$ 10 for belt and stream data, respectively.

${ }^{\mathrm{c}}$ We based test statistics and probabilities for the Wilcoxon paired-sample test on individual comparisons. The experiment-wise error rate based on 14 tailed frog and 6 torrent salamander comparisons presented here was $P=0.004$ and $P=0.009$, respectively.

between the 2 survey methods for all torrent salamander life stages and all tailed frog life stages except eggs, which occurred only in 2 belts in one stream. We calculated Pearson product-moment correlation matrices within and between survey methods for both belt and stream data. We used Pearson correlations rather than nonparametric rank correlations because, unlike rank correlation coefficients, Pearson coefficients can be squared (i.e., $r^{2}$ ) and used to measure the strength of the straight-line relationship between survey methods (Zar 1999). A straight-line relationship between methods suggests that one method is proportional to another over a range of densities and is thus a valid index of abundance. We based sample sizes on the highest number of target species-occupied belts (or streams) in each correlation pair. For example, analysis of all larvae (tailed frog) included abundance estimates from 29 rubbleroused belts each with $\geq 1$ animal present versus 29 lighttouched samples of which only 15 belts were occupied (we detected no animals with light-touch in remaining belts). We had no belts or streams where we found more animals using light-touch than rubble-rousing surveys, and we did not statistically analyze life-stage groups with sample sizes $<5$. We a priori set $\alpha=0.05$ and report comparison-wise error rates in the text and tables and experiment-wise error rates (Sokal and Rohlf 1981) only in the tables. Comparison-wise error rates are informative because we included here many comparisons (streams vs. belts, all life-history stages, and combinations of life stages) only for illustrative purposes and they were unlikely to be part of survey designs.

Occurrence.-We calculated capture efficiency as the proportion of occupied 1-m belts determined by light-touch when rubble-rousing detected $\geq 1$ animal. We did not analyze capture efficiency at the stream level because, given the patchy nature of occupancy across the stream, we were not able to standardize the sampling effort across streams (i.e., sample the same no. of $1-\mathrm{m}$ belts/stream). To determine how many light-touch samples would be needed to be as effective as a single rubble-rousing sample, we set the criteria that with $n$ samples of light-touch, the probability of not finding $\geq 1$ animal when an animal is present $(1-$ capture efficiency) is acceptably low (approx. 0$)$.

$$
P_{\mathrm{LT}}(0 \mid \geq 1)^{n} \approx 0,
$$

where $P_{\mathrm{LT}}(0 \mid \geq 1)$ is the probability of not finding an animal using light-touch sampling (when an animal is present), and $n$ is the number of light-touch samples.

Cost comparison.-To compare costs between rubblerousing and light-touch, we measured the time needed to complete each survey type. Time (min) began when 2 surveyors began a survey and concluded when they completed the survey for that site. To make valid comparisons between techniques, we removed the effect of total handling time because the 2 techniques were likely to capture different numbers of animals. We regressed total survey time (dependent variable) against number of animals found in a survey (independent variable) to derive an estimate of the time it took to do a survey with no handling time (i.e., $y$-intercept) for each survey technique. We excluded from the analysis 2 rubble-rousing belts that contained tailed frog eggs because the handling time per egg was very small relative to that of other life stages.

\section{RESULTS}

\section{Coastal Tailed Frog}

Light-touch abundance estimates by life stage for belt data were between $10 \%$ and $50 \%$ of rubble-rousing abundance estimates $(P \leq 0.018$ for all comparisons; Table 1). Similarly, light-touch abundance estimates by life stage for 
Table 2. Pearson product-moment correlation matrix between rubble-rousing- and light-touch-generated coastal tailed frog abundance estimates $\left(\right.$ no. $/ \mathrm{m}^{2}$ ) by life stage among $761-\mathrm{m}$ belts across 10 streams and among 10 streams of the Stillman Creek basin, Washington, USA, 2003.

\begin{tabular}{|c|c|c|c|c|c|c|c|c|c|c|c|c|}
\hline \multirow[b]{4}{*}{ Rubble-rousing } & \multicolumn{12}{|c|}{ Light-touch } \\
\hline & \multicolumn{2}{|c|}{ First-yr larvae } & \multicolumn{2}{|c|}{ Second-yr larvae } & \multicolumn{2}{|c|}{ All larvae } & \multicolumn{2}{|c|}{ Metamorphs } & \multicolumn{2}{|c|}{ Second-yr cohort } & \multicolumn{2}{|c|}{ All stages } \\
\hline & Belt & Stream & Belt & Stream & Belt & Stream & Belt & Stream & Belt & Stream & Belt & Stream \\
\hline & $n^{\mathrm{a}}=6$ & 3 & 12 & 6 & 15 & 7 & 8 & 6 & 18 & 8 & 22 & 8 \\
\hline First-yr larvae $(n=15,7)$ & -0.27 & -0.39 & -0.27 & -0.21 & -0.25 & -0.21 & -0.11 & -0.24 & -0.18 & -0.26 & -0.14 & -0.20 \\
\hline Second-yr larvae ${ }^{b}(17,7)$ & -0.14 & 0.11 & $0.59^{*}$ & $0.94^{* * *}$ & $0.48^{*}$ & $0.83^{*}$ & 0.19 & 0.62 & $0.68^{* * * *}$ & $0.96^{* * * *}$ & $0.60^{\text {*** }}$ & $0.93^{* * *}$ \\
\hline All larvae $^{c}(29,9)$ & -0.04 & 0.02 & 0.08 & 0.36 & 0.05 & 0.30 & 0.11 & 0.15 & 0.17 & 0.32 & 0.17 & 0.35 \\
\hline Metamorphs $(18,7)$ & $-0.43^{*}$ & -0.48 & $-0.50^{*}$ & -0.24 & $-0.45^{*}$ & -0.36 & -0.41 & 0.37 & $-0.47^{*}$ & 0.06 & $-0.36^{*}$ & 0.00 \\
\hline Second-yr cohort $(33,8)$ & -0.05 & -0.08 & $0.45^{*}$ & 0.70 & $0.36^{*}$ & 0.57 & 0.24 & $0.75^{*}$ & $0.50^{*}$ & $0.86^{*}$ & $0.46^{*}$ & $0.81^{*}$ \\
\hline All stages $(43,9)$ & -0.05 & -0.21 & -0.03 & -0.03 & -0.04 & -0.09 & 0.02 & 0.22 & 0.00 & 0.09 & -0.02 & 0.19 \\
\hline
\end{tabular}

${ }^{\text {a }}$ Sample sizes $(n)$ are the number of 1 -m belts or streams with that life stage present.

${ }^{\mathrm{b}}$ Second-year cohort is second-year larvae + metamorphs.

${ }^{\mathrm{c}}$ Indented life stage categories are composites of multiple life stages.

${ }^{*} P<0.05$, ${ }^{* *} P<0.005$, *** $P<0.001$, not corrected for multiple comparison. The experiment-wise error rate based on 36 belt (i.e., 6 life stages from light-touch $\times 6$ life stages from rubble-rousing) and 36 stream comparisons presented here was $P=0.001$ for each.

stream data were between $9 \%$ and $50 \%$ of rubble-rousing abundance estimates $(P \leq 0.043$ for all comparisons; Table 1). Except for eggs, light-touch detected all life stages found during rubble-rousing (Table 1). Based on rubble-rousing, correlations $(n=15)$ between life-stage abundances were low $(r<0.70)$ with 2 exceptions: 1$)$ between first-year larvae and all larvae (belt: $r=0.92, P<0.001$; stream: $r=0.82, P=$ 0.007); and 2) between second-year larvae and second-year cohort (belt: $r=0.71, P<0.001$; stream: $r=0.89, P=$ 0.003). Similarly, correlations $(n=15)$ between life-stage abundance as determined by light-touch were low with 6 exceptions. We found strong correlations between 1) second-year larvae and all larvae (belt: $r=0.89, P=0.001$; stream: $r=0.95, P<0.002)$; 2) second-year larvae and second-year cohort (stream: $r=0.89, P<0.004) ; 3$ ) secondyear larvae and all stages (stream: $r=0.91, P<0.002)$; 4) all larvae and second-year cohort (stream: $r=0.76, P=0.003$ ); 5) all larvae and all stages (belt: $r=0.71, P=0.001$; stream: $r$ $=0.84, P=0.009)$; and 6) second-year cohort and all stages (belt: $r=0.93, P<0.001$; stream: $r=0.96, P<0.001$ ).

Light-touch abundance estimates generally were not highly correlated with rubble-rousing abundance estimates, with 0 of 36 and 8 of 36 correlation coefficients for belts and streams, respectively, $\geq 0.7$ (Table 2). Abundance of second-year larvae using rubble-rousing was highly correlated with second-year larvae (stream: $r=0.94, P<0.005$ ), all larvae (stream: $r=0.83$, $P<0.05$ ), second-year cohort (stream: $r=0.96, P<0.001$ ), and all stages (stream: $r=0.93, P<0.001$ ) as determined by light-touch. In addition, abundance of second-year cohort using rubble-rousing stream data was highly correlated with second-year larvae $(r=0.70, P<0.06)$, metamorphs $(r=0.75$, $P<0.05)$, second-year cohort $(r=0.86, P<0.05)$, and all stages $(r=0.81, P<0.05)$ as determined from light-touch stream data. Importantly, no life-stage abundance that we estimated from light-touch was highly correlated with all larvae or all stages as determined by rubble-rousing.

\section{Columbia Torrent Salamander}

Similar to results for tailed frogs, light-touch salamander abundance estimates by life stage for belt data were between
$31 \%$ and $40 \%$ of rubble-rousing abundance estimates $(P \leq$ 0.027 for all comparisons; Table 1). Light-touch abundance estimates by life stage for stream data were between $38 \%$ and $40 \%$ of rubble-rousing abundance estimates $(P \leq 0.028$ for all comparisons; Table 1). Light-touch detected all life stages found during rubble-rousing (Table 1) but, in this case, neither method detected eggs.

Within-survey method correlations $(n=3)$ were low $(\leq 0.51)$ with one exception for each method. Abundance of premetamorphs was highly correlated with abundance of all life stages for light-touch (belt: $r=0.95, P<0.001$; stream: $r=0.97, P<0.001)$ and for rubble-rousing (belt: $r=0.96, P$ $<0.001$; stream: $r=0.98, P<0.001)$. We identified 4 cases for each of belt and stream data in which abundance estimates from rubble-rousing were highly correlated with abundance estimates from light-touch (Table 3): 1) for premetamorphs (belt: $r=0.75, P<0.001$; stream: $r=0.86$, $P<0.005$ ); 2) for all stages (belt: $r=0.80, P<0.001$; stream: $r=0.93, P<0.001)$; 3) between premetamorphs from light-touch and all life stages from rubble-rousing (belt: $r=0.74, P<0.001$; stream: $r=0.88, P<0.001$ ); and 4) vice versa (belt: $r=0.80, P<0.001$; stream: $r=0.90, P<$ $0.001)$.

\section{Occurrence}

The number of belts where we detected tailed frogs varied by life stage and survey method. Rubble-rousing frequency of occurrence estimates ranged from $3 \%$ of belts for eggs to $57 \%$ of belts for all life stages combined (Table 1 ), whereas light-touch frequency of occurrence estimates ranged from $0 \%$ for eggs to $29 \%$ for all life stages combined (Table 1 ). For tailed frogs capture efficiency was 0.00 for eggs, 0.33 for first-year larvae, 0.71 for second-year larvae, 0.52 for all larvae combined, 0.44 for metamorphs, 0.55 for second-year cohort, 0.44 for postmetamorphs, and 0.51 for all stages combined.

The frequency of occurrence estimates for torrent salamanders also varied by life stage and survey method. Rubble-rousing frequency of occurrence estimates of torrent salamanders ranged from $0 \%$ of belts for eggs to $42 \%$ of 
Table 3. Pearson product-moment correlation coefficients for rubble-rousing- and light-touch-generated Columbia torrent salamander abundance estimates $\left(\right.$ no. $\left./ \mathrm{m}^{2}\right)$ by life stage and life-stage group among 76 1-m belts across 10 streams and among 10 streams of the Stillman Creek basin, Washington, USA, 2003.

\begin{tabular}{|c|c|c|c|c|c|c|}
\hline \multirow[b]{4}{*}{ Rubble-rousing } & \multicolumn{6}{|c|}{ Light-touch } \\
\hline & \multicolumn{2}{|c|}{ Premetamorphs } & \multicolumn{2}{|c|}{ Postmetamorphs } & \multicolumn{2}{|c|}{ All stages } \\
\hline & Belts & Streams & Belts & Streams & Belts & Streams \\
\hline & $n^{\mathrm{a}}=16$ & 7 & 6 & 6 & 21 & 9 \\
\hline Premetamorphs $(n=25,10)$ & $0.75^{* *}$ & $0.86^{*}$ & 0.16 & 0.24 & $0.80^{* * *}$ & $0.90^{\text {*** }}$ \\
\hline Postmetamorphs $(10,7)$ & -0.03 & 0.44 & -0.09 & -0.09 & 0.07 & 0.51 \\
\hline All stages $(32,10)$ & $0.74^{* *}$ & $0.88^{* *}$ & 0.25 & 0.34 & $0.80^{* * *}$ & $0.93^{* *}$ \\
\hline
\end{tabular}

${ }^{a}$ Sample size $(n)$ refers to the number of belts and streams with that life stage present.

${ }^{*} P<0.005$, ** $P<0.001$, not corrected for multiple comparison. The experiment-wise error rate based on 9 belt (i.e., 3 life stages from light-touch $\times 3$ life stage from rubble-rousing) and 9 stream comparisons presented here was $P=0.006$ for each.

belts for all life stages combined (Table 1), whereas lighttouch frequency of occurrence estimates ranged from $0 \%$ of belts for eggs to nearly $28 \%$ of belts for all life stages combined (Table 1). Capture efficiency of light-touch was 0.55 for each of pre- and postmetamorphs, with an overall efficiency of 0.66 for all stages.

Using light-touch, the rate of false-negative errors declined exponentially with increases in sample size. With 16 light-touch samples and an overall capture efficiency of 0.51 for tailed frogs (Table 4; i.e., $P_{\mathrm{LT}}(0 \mid \geq 1)=0.49$ ), the probability of wrongly concluding tailed frogs were absent assuming they could be found with rubble-rousing was 0.00001. Likewise, with 11 light-touch samples and an overall capture efficiency of 0.66 , the probability of wrongly concluding torrent salamanders were absent was 0.00001 (Table 4).

\section{Cost Comparison}

The regression equations relating survey time $(Y)$ to the number of animals handled during a survey $(X)$ was $Y=3.22$ $+1.39 X\left(F_{1,75}=40.33, P<0.001\right)$ for light-touch and $Y=$ $39.13+2.10 X\left(F_{1,72}=10.67, P=0.002\right)$ for rubble-rousing. On average, 2 surveyors required $3.22 \pm 0.42(\mathrm{SE})$ minutes to search a 1-m belt using light-touch and $39.14 \pm 4.29$ (SE) minutes to search a $1-\mathrm{m}$ belt using rubble-rousing, excluding animal-handling time. The ratio of rubblerousing to light-touch survey time was 12.2 (i.e., it takes slightly over 12 times as long to do rubble-rousing as to do light-touch surveys).

\section{DISCUSSION}

Valid abundance survey methods either enumerate all individuals or a constant proportion of individuals across samples in space and time. We used correlations to test the assumption that the light-touch surveys sample a constant proportion of individuals caught during rubble-rousing surveys and is, therefore, a technique that produces valid indices of abundance. The larger the correlation coefficient, the better light-touch met this critical assumption. Lighttouch surveys can be thought of as a subset of rubble-rousing in the sense that rubble-rousing includes searching the streambed in a manner identical to light-touch before proceeding to searching within the substrate. If surfaceactive individuals represent a constant proportion of animals at a site, then light-touch should provide a valid index of abundance.

The value of light-touch surveys for estimating abundance was species- and life stage-specific. For tailed frog, lighttouch abundance estimates were poorly correlated with rubble-rousing estimates except for second-year larvae. On this basis one could conclude that light-touch surveys provided a reasonable index of abundance for second-year tailed frog larvae despite the fact that light-touch only detected about half the second-year larvae found with rubble-rousing. Unfortunately, because correlations between second-year larvae and other life stages were low as determined by rubble-rousing, knowing the abundance of second-year larvae says little about abundance of any other single life stage. Indeed, most relationships between life stages within a survey type were relatively uninformative. For example, we found low correlations between single tailed frog life stages as determined by rubble-rousing and between first- and second-year larvae as determined by light-touch.

Light-touch sampled a larger proportion of second-year tailed frog larvae (relative to rubble-rousing) than any other life stage. Second-year tailed frog larvae are more easily

Table 4. Sample guidelines, in number of 1 -m belts, for substituting lighttouch for rubble-rousing to determine species occurrence. False-negative error rate measures the probability of not finding at least one individual of a species when that species is present, and is based on light-touch capture probabilities of 0.51 and 0.64 for coastal tailed frog and Columbia torrent salamander, respectively, from the Stillman Creek basin, Washington, USA, 2003.

\begin{tabular}{lcc}
\hline \multirow{2}{*}{$\begin{array}{c}\text { False-negative error rate } \\
\text { (risk tolerance) }\end{array}$} & \multicolumn{2}{c}{ No. of 1-m belts } \\
\cline { 2 - 3 } & Tailed frog & Torrent salamander \\
\hline 0.1 & 3 & 2 \\
0.01 & 6 & 4 \\
0.001 & 10 & 7 \\
0.0001 & 13 & 9 \\
0.00001 & 16 & 11 \\
0.000001 & 19 & 13 \\
0.0000001 & 23 & 15 \\
\hline
\end{tabular}


detected than some other life stages (i.e., eggs and first-yr larvae; Kelsey 1995). Greater surface activity is consistent with the feeding behavior of second-year larvae, which graze on the algal film on rocks within the stream channel that are typically exposed to light (Gradwell 1971, Nussbaum et al. 1983). Second-year tailed frog larvae may also be more detectable than postmetamorphic life stages during diurnal surveys such as those we applied because postmetamorphic life stages are thought to be more nocturnal (Nussbaum et al. 1983).

Light-touch surveys seemed better suited to estimating torrent salamander abundance than tailed frog abundance. Between-survey correlations were high $(R>0.80)$ for the larval stages and all stages combined. Again, one advantage of using light-touch rather than rubble-rousing to estimate torrent salamander abundance is that light-touch can provide broader spatial coverage than rubble-rousing at the same cost.

Our correlation analyses should be interpreted cautiously. Correlations between single life stages and life-stage groups within a survey type sometimes were driven by the fact that most data for the grouped life stage came from one life stage. For example, rubble-rousing data showed that second-year tailed frog larvae composed greater than $50 \%$ of the observations that made up the all-larvae class. Small sample sizes or the disproportionate influence of a single sample warrant additional caution. Finally, a lack of correlation within a survey type may be the result of a combination of life stage-specific habitat use and the size of a sample belt (1-m length). If different life stages of tailed frog use different habitats, then correlations between those life stages would be low when the survey area (here a 1-m belt) only encompasses one habitat type. This may explain why correlation coefficients from stream data generally were higher than coefficients for belt data. Finally, our findings can only be applied to our 2 target species and only from areas within Washington State where we conducted our study.

Light-touch has been used to address the concern that the cost of rubble-rousing limits its application to a very small portion of a stream that may not be representative of habitat conditions over the area of interest (see Barr and Babbitt 2001). Additionally, rubble-rousing is destructive in the sense that it results in reductions of fine sediments (as they often wash away during the survey) and re-sorting of larger substrates in the sample reach. These changes can confound the effects of forest management activities (the study objective of much headwater amphibian work), which also can often increase the delivery of fine sediments to the stream. On the other hand, light-touch surveys sacrifice thoroughness at a few sites for sampling across a much broader area of the stream and presumably a broader array of habitat types. Light-touch has a much lower likelihood of altering the streambed.

\section{MANAGEMENT IMPLICATIONS}

For both species we examined, we found it more costefficient to use light-touch than rubble-rousing to determine occurrence assuming some small risk of false-negative errors. Moreover, the false-negative error rate can be readily calculated from our capture efficiency data and set at levels appropriate to different study designs and the degree of risk one is willing to tolerate. If amphibians are patchy in their distribution, then light-touch may have an added advantage of sampling across a wider variety of habitat types in the stream that fewer more expensive rubble-rousing samples could miss. Despite its advantage at determining occurrence, however, light-touch is unlikely to reveal life stages that are buried in substrate, such as eggs of tailed frogs or torrent salamanders.

\section{ACKNOWLEDGMENTS}

Funding was provided through the Adaptive Management Program of the Washington State Forests and Fish Agreement. Through A. Melchiors, the Weyerhaeuser Company gave permission to conduct the study on their lands. J. M. Kozma, A. J. Kroll, K. L. Krueger, and J. G. MacCracken reviewed various drafts of this manuscript. R. L. Baker, A. C. Basey, A. Eaton-Mordas, D. R. Jacobson, M. R. Kluber, A. Palmeri-Miles, R. D. Nauer, S. M. Price, B. M. Tropp, E. P. Urling, and D. D. Morrow assisted in the field.

\section{LITERATURE CITED}

Adams, M. J., and R. B. Bury. 2002. The endemic headwater stream amphibians of the American Northwest: associations with environmental gradients in a large forested preserve. Global Ecology and Biogeography 11:169-178.

Barr, G. E., and K. J. Babbitt. 2001. A comparison of 2 techniques to sample larval stream salamanders. Wildlife Society Bulletin 29:12381242.

Beaupre, S. B., E. R. Jacobson, H. B. Lillywhite, and K. Zamudio. 2004. Guidelines for use of live amphibians and reptiles in field and laboratory research. Second revised edition. Herpetological Animal Care and Use Committee (HACC), American Society of Ichthyologists and Herpetologists, Lawrence, Kansas, USA.

Bury, R. B., and M. J. Adams. 1999. Variation in age at metamorphosis across a latitudinal gradient for the tailed frog, Ascaphus truei. Herpetologica 55:283-291.

Bury, R. B., and P. S. Corn. 1991. Sampling methods for amphibians in streams in the Pacific Northwest. U.S. Forest Service General Technical Report PNW-GTR-275, Pacific Northwest Research Station, Portland, Oregon, USA.

Bury, R. B., P. S. Corn, K. A. Aubry, F. F. Gilbert, and L. L. C. Jones. 1991. Aquatic amphibian communities in Oregon and Washington. Pages 353-362 in L. F. Ruggiero, K. B. Aubry, A. B. Carey, and M. H. Huff, technical coordinators. Wildlife and vegetation of unmanaged Douglas-fir forests. U.S. Forest Service General Technical Report PNWGTR-285, Pacific Northwest Research Station, Portland, Oregon, USA.

Crump, M. L., and N. J. Scott, Jr. 1994. Visual encounter surveys. Pages 84-91 in W. R. Heyer, M. A. Donnelly, R. W. McDiarmid, L.-A. C. Hayek, and M. S. Foster, editors. Measuring and monitoring biological diversity: standard methods for amphibians. Smithsonian Institution Press, Washington, D.C., USA.

Diller, L. V., and R. L. Wallace. 1996. Distribution and habitat of Rhyacotriton variegatus in managed, young growth forests in north coastal California. Journal of Herpetology 30:385-398.

Downes, B. J. 1990. Patch dynamics and mobility of fauna in streams and other habitats. Oikos 59:411-413.

Dvornich, K. M., K. R. McAllister, and K. B. Aubry. 1997. Amphibians and reptiles of Washington State: location data and predicted distributions. Volume 2 in K. M. Cassidy, C. E. Grue, M. R. Smith 
and K. M. Dvornich, editors. Washington State gap analysis-final report. Washington Cooperative Fish and Wildlife Research Unit, University of Washington, Seattle, USA.

Franklin, J. F., and C. T. Dyrness. 1973. Natural vegetation of Oregon and Washington. U.S. Forest Service General Technical Report PNWGTR-8, Pacific Northwest Research Station, Portland, Oregon, USA.

Gradwell, N. 1971. Ascaphus tadpole: experiments on the suction and gill irrigation mechanisms. Canadian Journal of Zoology 49:307-332.

Hayek, L.-A. C. 1994. Research design for quantitative amphibian studies. Pages 21-39 in W. R. Heyer, M. A. Donnelly, R. W. McDiarmid, L.-A. C. Hayek, and M. S. Foster, editors. Measuring and monitoring biological diversity: standard methods for amphibians. Smithsonian Institution Press, Washington, D.C., USA.

Hayes, M. P., T. Quinn, L. Diller, L. L. C. Jones, J. G. MacCracken, M. J. Raphael, and D. E. Runde. 2001. Evaluation of sampling methods for amphibians in headwater basins of non-fishbearing streams: a preliminary analysis. Year 2000 annual report, Washington Department of Natural Resources, Forest Practices Division, Olympia, USA.

Jackson, C. R., C. A. Sturm, and J. M. Ward. 2001. Timber harvest impacts on small headwater stream channels in the Coast Ranges of Washington. Journal of the American Water Resources Association 37:1533-1549.

Kelsey, K. A. 1995. Responses of headwater stream amphibians to forest practices in western Washington. Dissertation, University of Washington, Seattle, USA.

Lancia, R. A., J. D. Nichols, and K. H. Pollock. 1996. Estimating the number of animals in wildlife populations. Pages 215-253 in T. A. Bookhout, editor. Research and management techniques for wildlife and habitats. Fifth edition, revised. The Wildlife Society, Bethesda, Maryland, USA.

Lowe, W. H., and D. T. Bolger. 2002. Local and landscape-scale predictors of salamander abundance in New Hampshire headwater streams. Conservation Biology 16:183-193.

Nussbaum, R. A., E. D. Brodie, Jr., and R. M. Storm. 1983. Amphibians and reptiles of the Pacific Northwest. University Press of Idaho, Moscow, USA.

Pauley, T. K., and M. Little. 1998. A new technique to monitor larval and juvenile salamanders in stream habitats. Banisteria 12:32-36.

Russell, K. C., T. J. Mabee, and M. B. Cole. 2004. Distribution and habitat of Columbia torrent salamanders at multiple spatial scales in managed forests of northwestern Oregon. Journal of Wildlife Management 68: 405-417.

Sokal, R. R., and F. J. Rohlf. 1981. Biometry. Second edition. W. H. Freeman, New York, New York, USA.

Stebbins, R. C. 2003. A field guide to western reptiles and amphibians. Third edition. Houghton Mifflin, Boston, Massachusetts, USA.

Steele, C. A., E. D. Brodie, Jr., and J. G. MacCracken. 2003. Relationships between abundance of cascade torrent salamanders and forest age. Journal of Wildlife Management 67:447-453.

Strahler, A. N. 1952. Hypsometric (area-altitude) analysis of erosion topography. Bulletin of the Geological Society of America 63:1117-1142.

Sumioka, S. S., D. L. Kresch, and K. D. Kasnick. 1998. Magnitude and frequency of floods in Washington. U.S. Geological Survey Water Resources Investigations Report 97-4277, Tacoma, Washington, USA.

Thoms, C., C. C. Corkran, and D. H. Olson. 1997. Basic amphibian survey for inventory and monitoring of lentic habitats. Pages 35-46 in D. H. Olson, W. P. Leonard, and R. B. Bury, editors. Sampling amphibians in lentic habitats. Society for Northwestern Vertebrate Biology, Northwest Fauna 4, Olympia, Washington, USA.

Wells, R. E. 1981. Geologic map of the eastern Willapa Hills: Cowlitz, Lewis, Pacific, and Wahkiakum Counties, Washington. Department of the Interior, U.S. Geological Survey Open File Report 81-674, prepared in cooperation with the State of Washington Department of Natural Resources, Division of Geology and Earth Resources, Olympia, USA.

Welsh, H. H., Jr., and A. J. Lind. 1996. Habitat correlates of the southern torrent salamander, Rhyacotriton variegatus (Caudata: Rhyacotritonidae), in northwestern California. Journal of Herpetology 30:385-398.

Welsh, H. H., Jr., L. M. Ollivier, and D. G. Hankin. 1997. A habitat-based design for sampling and monitoring stream amphibians with an illustration from Redwood National Park. Northwestern Naturalist 78: $1-16$.

Wilkins, R. N., and N. P. Peterson. 2000. Factors related to amphibian occurrence and abundance in headwater streams draining second-growth Douglas-fir forests in southwestern Washington. Forest Ecology and Management 139:79-91.

Zar, J. H. 1999. Biostatistical analysis. Fourth edition. Prentice-Hall, Upper Saddle River, New Jersey, USA.

Associate Editor: Perry. 
